\title{
EXPERIMENTAL STUDY OF THE INLET FLOW IN A NON- PREMIXED COMBUSTION CHAMBER
}

\author{
B. P. Trevisan ${ }^{\mathrm{a}}$, \\ and W. M. C. Douradob \\ ${ }^{a}$ Instituto Nacional de Pesquisas Espaciais \\ Laboratório Associado de Combustão e Propulsão \\ Rodovia Presidente Dutra, km 40 \\ CEP 12630-000, Cachoeira Paulista, São Paulo, Brasil \\ bruno.trevisan@gmail.com \\ ${ }^{\mathrm{b}}$ Instituto de Aeronáutica e Espaço \\ Divisão de Propulsão \\ Praça Mal. Eduardo Gomes, 50, Vila das Acácias \\ CEP12228-904, São José dos Campos, São Paulo, Brasil \\ wladimyrwmcd@fab.mil.br \\ Received: May 24, 2019 \\ Revised: June 29, 2019 \\ Accepted: May 13, 2020
}

ABSTRACT

The evaluation, validation and development of the models used in computation fluid dynamics requires the availability of experimental data for which the boundary conditions, especially the conditions of the inlet flow, are well defined. Laser diagnostics techniques provide experimental data used in computational fluid dynamics and are a powerful tool for measurements of the mean properties and fluctuations of the turbulent flow because they are non-intrusive methods, with high repetition rate and high spatial and temporal resolution. Therefore, in the present work an experimental study of the inlet flow (inert and combusting flows) in a non-premixed combustion chamber is presented. The velocity measurements were carried out using a laser Doppler velocimeter at the entrance region of the combustion chamber. An asymmetry on the mean flow and an increase on the total velocity fluctuations with the increase of the equivalence ratio was observed. The major effect on the increase of the equivalence ratio was a presence of a coherent movement on large scales associated to the flame brush dynamics.

Keywords: non-premixed combustion; turbulence; laser doppler velocimetry

\section{NOMENCLATURE}

BEIC banco de estudos de instabilidade de combustão

CFD computational fluid dynamics

ESD energy spectral density

$F \quad$ flatness factor

FFT fast Fourier transform

h channel height, $\mathrm{mm}$

i inert flow

PDF probability density function

$Q \quad$ air mass flow, g/s

$q \quad$ fuel mass flow, $\mathrm{g} / \mathrm{s}$

$r \quad$ reacting flow

$\mathrm{R}_{\text {ebulk }}$ Reynolds number based on bulk velocity

$S \quad$ skewness factor

$u \quad$ longitudinal velocity, $\mathrm{m} / \mathrm{s}$

$U_{\text {bulk }}$ bulk velocity, $\mathrm{m} / \mathrm{s}$

$v$ normal velocity, $\mathrm{m} / \mathrm{s}$

$x \quad$ longitudinal direction, $\mathrm{mm}$

$y \quad$ normal direction, $\mathrm{mm}$

\section{Greek symbols}

$v \quad$ viscosity, $\mathrm{kg} / \mathrm{ms}$

\section{Superscripts}

velocity fluctuation
- $\quad$ mean velocity

\section{INTRODUCTION}

The validation and development of physical models used in computational fluid dynamics (CFD) requires well defined boundary conditions, especially the conditions of the inlet flow, not only for the mean quantities but also for the unsteady properties associated with these mean values. In this context, the flow boundary conditions, particularly the conditions of the inlet flow, must be determined experimentally with accuracy (Besson et al., 2000; Sanquer et al., 1998). The experimental database provided by Sanquer et al. (1998) was used by Dourado (2003) to validate and develop a numeric model for turbulent flows while Souza (2015) used the experimental database by Besson (2001) and Nguyen et al. (2009) in a numerical study.

Experimental studies in a premixed dump combustor (Besson et al., 2000; Nguyen et al., 2009) and in a bluff-body-stabilized premixed flames (Sanquer et al., 1998) showed, for some specifics equivalence ratio, the appearance of a periodic motion in the incoming flow. This periodic motion is associated with the combustion instabilities and it is well known for premixed dump combustor and for bluff-body-stabilized premixed flames (Schadow and Gutmark, 1992). In aerospace engine combustors, these instabilities can lead to vibrations, severe 
degradation of the combustion process, heat transfer increase and so on. In particularly severe cases, the engine or the propulsion system can be damaged or destroyed (Gianni et al., 2003; Habiballah et al., 1998).

Therefore, the knowledge and control of the physical phenomena related to combustion instability is needed to design and analyzed more efficient and reliable equipment. The advanced laser-based diagnostics provide insight into these interactions and experimental data used in development and validation of physical models used in computational fluid dynamics. These techniques are little intrusive with high temporal and spatial resolution that facilitates quantitative measurements of the mean properties and unsteady properties of the turbulent flow (Janus et al., 2007). Normally these data are obtained from simplified combustion device designed to provide experimental access (Hassel and Linow, 2000; Steinberg et al., 2010).

Despite the fact that the mechanisms associated with the combustion instabilities for premixed dump combustor or bluff-body-stabilized premixed flames is well known (Schadow and Gutmark, 1992), experiments using non-premixed flames are more difficult and few information can be found. Considering that experiments on diffusion flames are in high demand, the combustion instability test facility named Banco de Estudos de Instabilidade de Combustão (BEIC) has been designed and developed as part from the development of the L-75 engine at Instituto de Aeronáutica e Espaço (IAE) with the objective of understanding combustion instability phenomenon in non-premixed flames and building up an experimental database for the computational fluid dynamics.

The purpose of the present experimental study is to evaluate the influence of the combustion on the flow at the inlet of a non-premixed combustion chamber and provide, through velocity measurements, a comparison between inert and reacting flow in terms of their mean and unsteady properties.

\section{EXPERIMENTAL SETUP}

An overview of the BEIC is presented in Fig. 1. The BEIC is a combustion instability test facility with a non-premixed atmospheric combustion chamber and includes four main sections: 1) a 1.02-m-long section of a constant quadratic cross section required to obtain fully developed turbulent channel flow, 2) a fuel injector head, 3) a 0.55-m-long non-premixed atmospheric combustion chamber with thermally insulated walls and 4) an exhaust section that follows the combustion chamber.
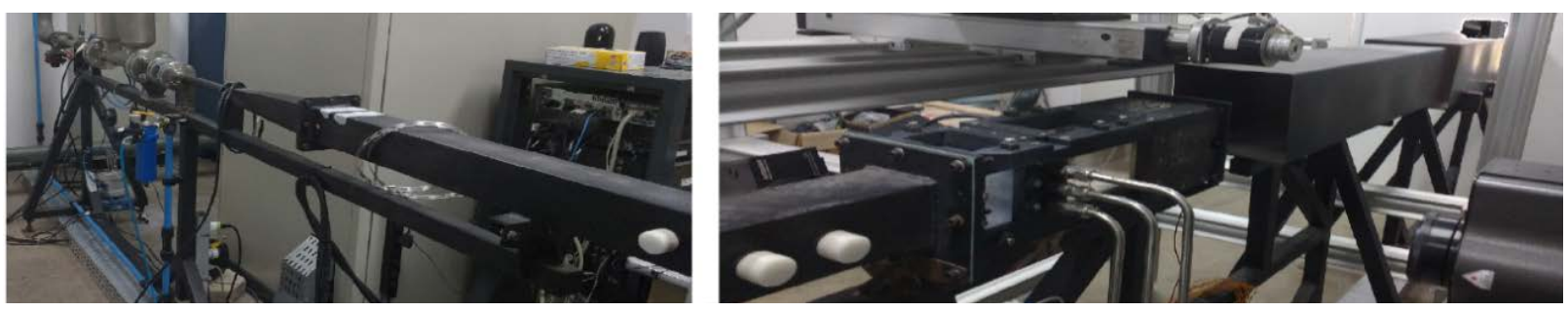

Figure 1. An overview of the BEIC.

The air is supplied by a blower and the air flow is controlled by two valves to avoid the increase in pressure and, consequently, in the air temperature. The combustion chamber (Fig. 2) has windows that provide optical access and can be divided in two regions: the entrance region, that is positioned upstream of the fuel injectors and the main region that is positioned downstream. The characteristic dimensions of the combustion chamber are given in Fig. 3. The fuel (commercial propane at 99\% purity) is injected in the combustion chamber by three 12$\mathrm{mm}$ height injectors. Each injector provides the fuel through at two $0.3-\mathrm{mm}$ thickness slots forming two flat and parallel jets. More information about the test facility can be found in Trevisan (2018).

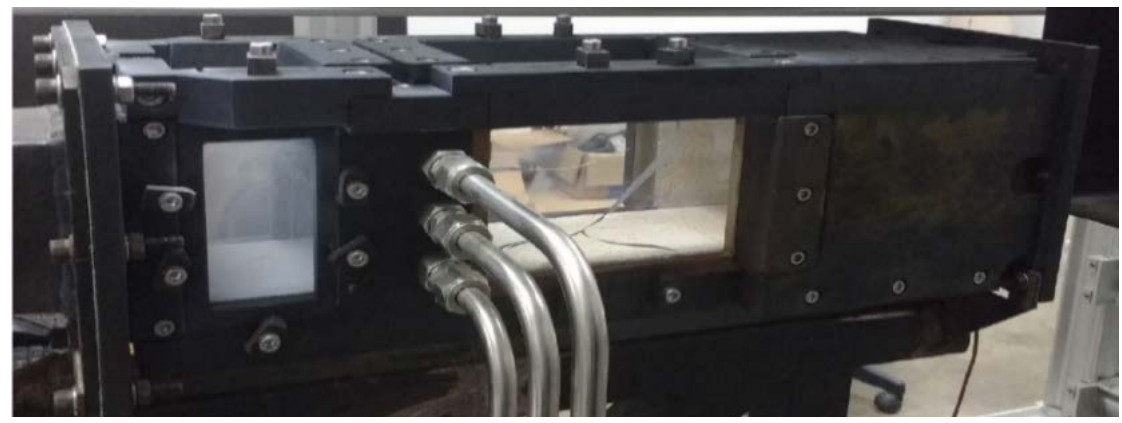

Figure 2. Combustion chamber. 


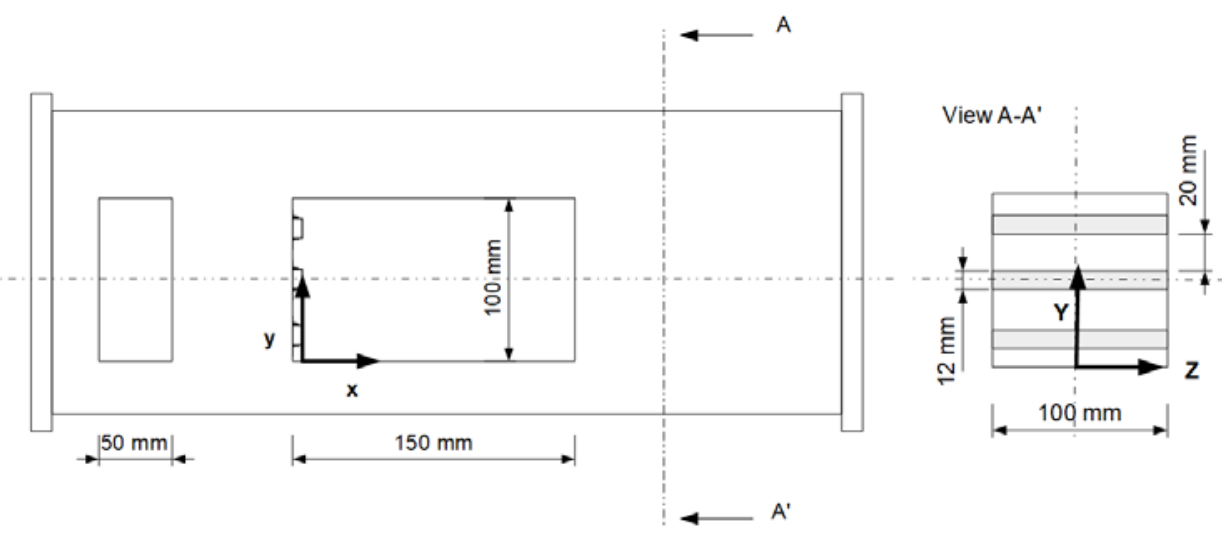

Figure 3. Characteristic dimensions of the combustion chamber.

\section{FLOW PARAMETERS, MEASUREMENT EQUIPMENT AND DATA PROCESSING}

The main parameters of the cases studied are listed in the Tab. 1. Case $i$ corresponds to an inert flow, whereas $r_{1}$ and $r_{2}$ correspond to the reacting flow. The visualization of the combustion zone of the cases $r_{1}$ and $r_{2}$ are shown, respectively, in Figs. 4 and 5 . The mass flow rate of the incoming air flow is $\dot{Q}$ and the mass flow rate of the fuel flow is $\dot{q}$. The bulk velocity ( $U_{b u l k}$ ) has been calculated with the total air mass flow rate and the Reynolds number is defined by:

$$
\operatorname{Re}_{\text {bulk }}=U_{\text {bulk }}(h / v)
$$

where $h=100 \mathrm{~mm}$ is the channel height.

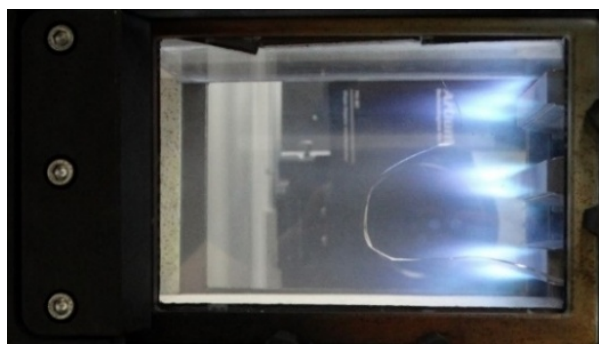

Figure 4. Visualization of the combustion zone for case $r_{1}$.

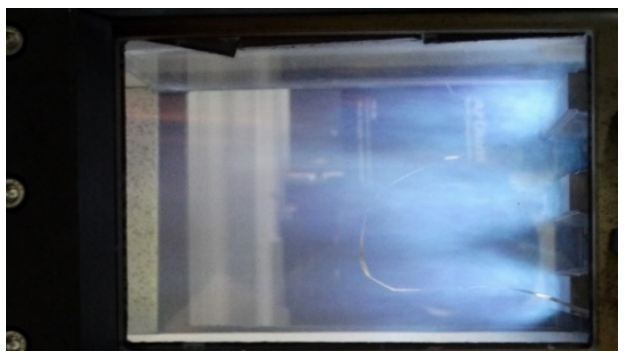

Figure 5. Visualization of the combustion zone for case $r_{2}$.
Table 1. Main parameters of the flows (random error in $\dot{Q}= \pm 2 \mathrm{~g} / \mathrm{s}$ and in $\dot{q}= \pm 0.02 \mathrm{~g} / \mathrm{s}$, relative

\begin{tabular}{ccccc}
\multicolumn{4}{l}{ uncertainty in $U_{\text {bulk }}= \pm 0.2 \mathrm{~m} / \mathrm{s}$ and $\left.\mathrm{Re}_{\text {bulk }}= \pm 3 \%\right)}$. \\
\hline Case & $\dot{Q}(\mathrm{~g} / \mathrm{s})$ & $\dot{q}(\mathrm{~g} / \mathrm{s})$ & $\begin{array}{l}U_{\text {bulk }} \\
(\mathrm{m} / \mathrm{s})\end{array}$ & $\mathrm{Re}_{\text {bulk }}$ \\
\hline$i$ & 80 & - & 6.7 & 43226 \\
$r_{1}$ & 80 & 0.92 & 6.7 & 43226 \\
$r_{2}$ & 80 & 1.44 & 6.7 & 43226 \\
\hline
\end{tabular}

The velocity measurement was carried out with a 2D four-beam two colors laser Doppler velocimeter (LDV), model PDI 300 by Artium Technologies. The beams are frequency shifted by Bragg cells to avoid any directional ambiguity. The main characteristics of the system are listed in Tab. 2.

Table 2. Main characteristics of the LDV system.

\begin{tabular}{ccc}
\hline Characteristics & Green Laser & Blue Laser \\
\hline $\begin{array}{c}\text { Wavelength } \\
\text { (nm) }\end{array}$ & 532 & 491 \\
$\begin{array}{c}\text { Transmitting } \\
\text { focal lens (mm) } \\
\text { Beams } \\
\text { intersection } \\
\text { angle ( }{ }^{\circ} \text { ) }\end{array}$ & 500 & 500 \\
$\begin{array}{c}\text { Beam waist } \\
\text { diameter (mm) }\end{array}$ & 322.6 & 312.6 \\
$\begin{array}{c}\text { Fringe spacing } \\
\text { ( } \mu \text { m) }\end{array}$ & 4.4 & 4.0 \\
$\begin{array}{c}\text { Probe volume } \\
\text { diameter (mm) } \\
\text { Probe volume } \\
\text { length (mm) }\end{array}$ & 0.32 & 0.31 \\
\hline
\end{tabular}

The two velocity components ( $u$ for the longitudinal $\mathrm{x}$-direction and $v$ for the normal $\mathrm{y}$ direction) were measured in the forward-scattering mode. In all cases, the flow was seeded with $\mathrm{S}_{\mathrm{i}} \mathrm{O}_{2}$ and $\mathrm{T}_{\mathrm{i}} \mathrm{O}_{2}$ particles. The laser probes were displaced by a traversing system. The processes of acquisition, probe displacement and data processing were controlled by the software AIMS by Artium 
Technologies. All the velocity measurements were carried out in the middle of the entrance region ( $x=-120 \mathrm{~mm}$ ) and in the plane $z=0 \mathrm{~mm}$.

In the present system, the principal source of systematic error is due to the uncertainty associated with the measuring volume positioning and the velocity bias. The principal source of random error is associated with the statistical uncertainty of the signal sampling. Taking into account the geometric characteristics of the effective measuring volume and of the displacement system, the systematic error in determining the location of the measuring volume is estimated to be equal to $\pm 0.5 \mathrm{~mm}$. The statistical bias of the measured velocity towards higher values was corrected by using a weighted average (Albrecht et al., 2003). This procedure is implemented here by using the arrival time as the weighting factor. The random errors were estimated by determining a $95 \%$ confidence interval by using the formulas given by Benedict and Gould (1996).

The slotting technique with a local normalization, to reduce the high variance of the technique, was used to determining the time autocorrelation function (Albrecht et al., 2003; Van Maanen and Tummers, 1996). A sample and hold reconstruction were used to reconstruct the LDV signal then a fast Fourier transform is performed to obtain the ESD (Albrecht et al., 2003). This procedure is necessary because the LDV signal are irregular in time, so reconstruction methods are needed to obtain the fast Fourier transform (FFT) of the signal and, consequently, the Energy Spectral Density (ESD)

\section{RESULTS AND DISCUSSION}

The profiles, obtained in the entrance region, of the two mean velocities components $\bar{u}$ and $\bar{v}$ and of the corresponding rms-velocity flutuations normalised by the bulk velocity for the three cases are shown in Figs. 6-9. The profiles of $\bar{u} / U_{\text {bulk }}$ in Fig. 6 are typical of those of a fully developed turbulent channel flow and show the symmetry of the mean flow for the cases $i$ and $r_{1}$. In case $r_{2}$, the profile is found to be asymmetric relative to the centerline of the test bench. The profiles of $\bar{v} / U_{\text {bulk }}$

(Fig. 7) are all quasi-similar regardless of the flow considered and are close to the expected value $\bar{v}=0$. For the longitudinal rms-velocity fluctuations (Fig. 8 ), the profiles in the cases $i$ and $r_{1}$ are similar and exhibit a maximum value near to the wall due to the parietal shear. For the case $r_{2}$, the profile exhibits an important increase in the longitudinal rms-velocity fluctuations and the maximum value near to the wall is not notice anymore. Differently from what is observed for the longitudinal rms-velocity fluctuations $u^{\prime}$, the profile of the normal rmsvelocity fluctuations $v^{\prime}$ (Fig. 9) presents the same order of magnitude for all cases studied. For the case $r_{2}$, the combustion process developed in the main region of the combustion chamber is influencing the flow upstream of the flame holder. This can be related to the pulsating behaviour of the flame observed in this case (Sanquer et al., 1998).

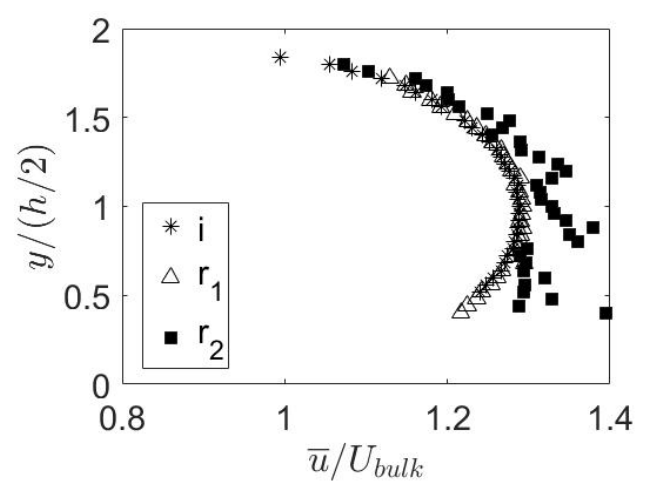

Figure 6. Profiles of the mean longitudinal velocity. (Systematic error in $y= \pm 0.5 \mathrm{~mm}$, maximum random error in $\bar{u}= \pm 0.04 \mathrm{~m} / \mathrm{s}$ ).

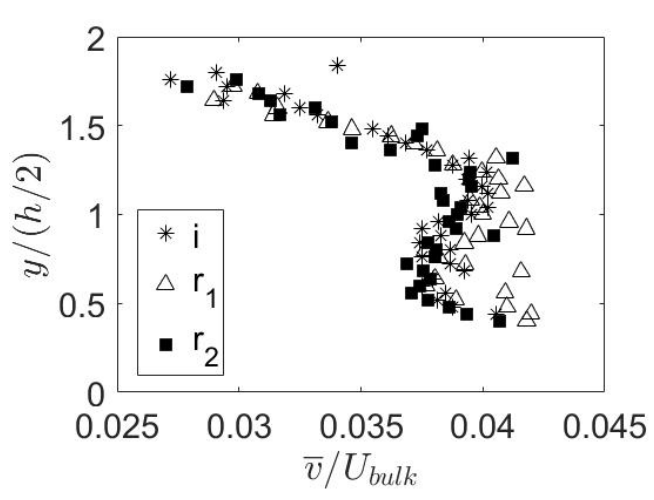

Figure 7. Profiles of the mean normal velocity. (Systematic error in $y= \pm 0.5 \mathrm{~mm}$, maximum random error in $\bar{v}= \pm 0.01 \mathrm{~m} / \mathrm{s}$ ).

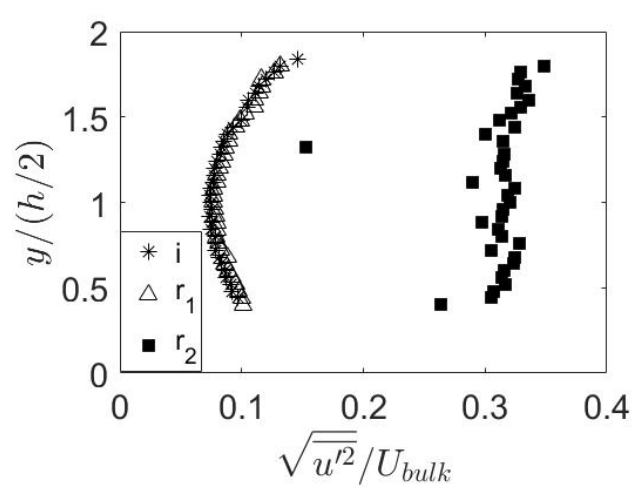

Figure 8. Profiles of the longitudinal rms-velocity fluctuations. (Systematic error in $y= \pm 0.5 \mathrm{~mm}$, maximum random error in $\sqrt{\overline{u^{\prime 2}}}= \pm 0.02 \mathrm{~m} / \mathrm{s}$ ). 


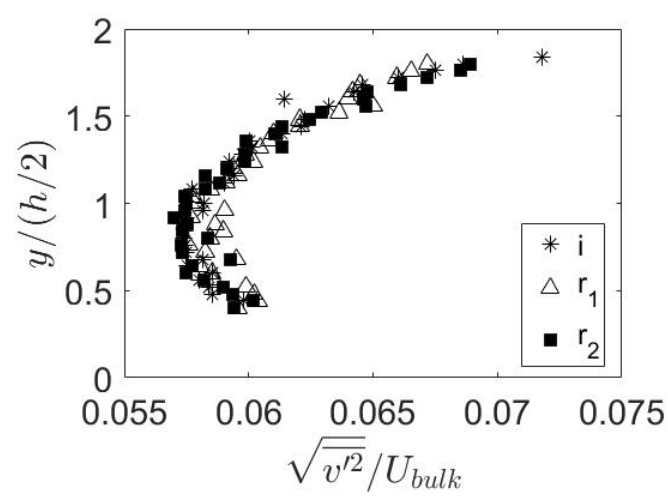

Figure 9. Profiles of the normal rms-velocity fluctuations. (Systematic error in $y= \pm 0.5 \mathrm{~mm}$, maximum random error in $\sqrt{\overline{v^{\prime 2}}}= \pm 0.006 \mathrm{~m} / \mathrm{s}$ ).

Figures 10 and 11 present the time autocorrelation function of the two velocities components $\bar{u}$ and $\bar{v}$ obtained at entrance region on the axis of the channel $(y= \pm 0.5 h)$. The same behaviour is observed in the cases $i$ and $r_{1}$, this is a typical behaviour of the auto-correlations functions in fully developed turbulence. For the case $r_{2}$, the time autocorrelation function shows a periodic behavior. The incoming flow exhibit a pulsation, which is stronger in the longitudinal direction.
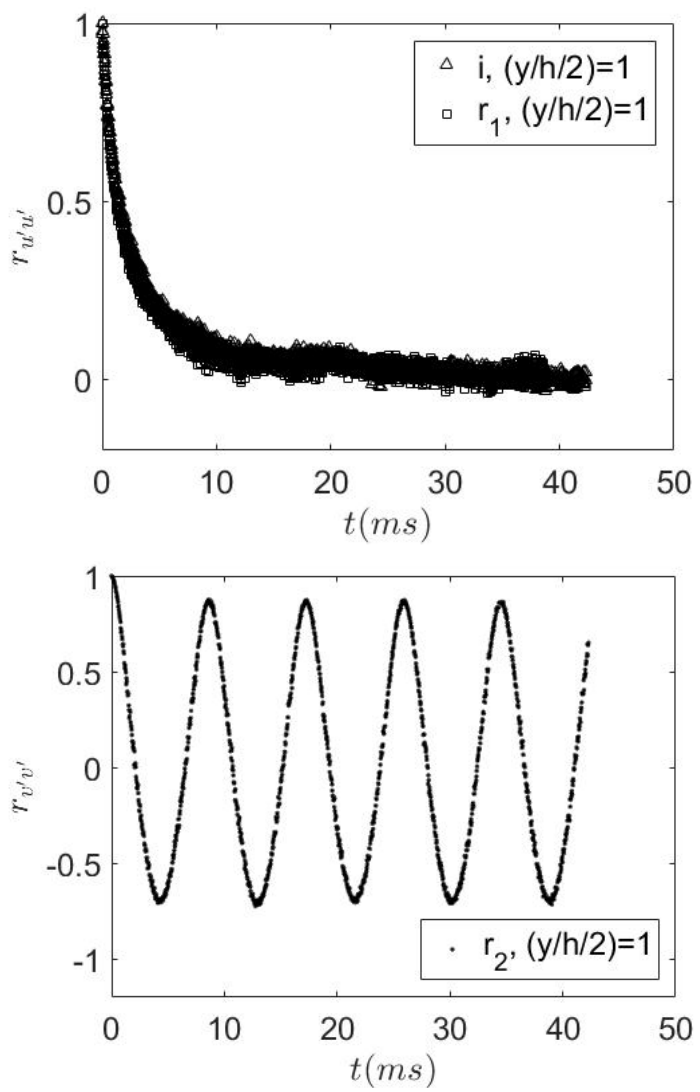

Figure 10. Auto-correlation functions of the longitudinal rms-velocity fluctuations.
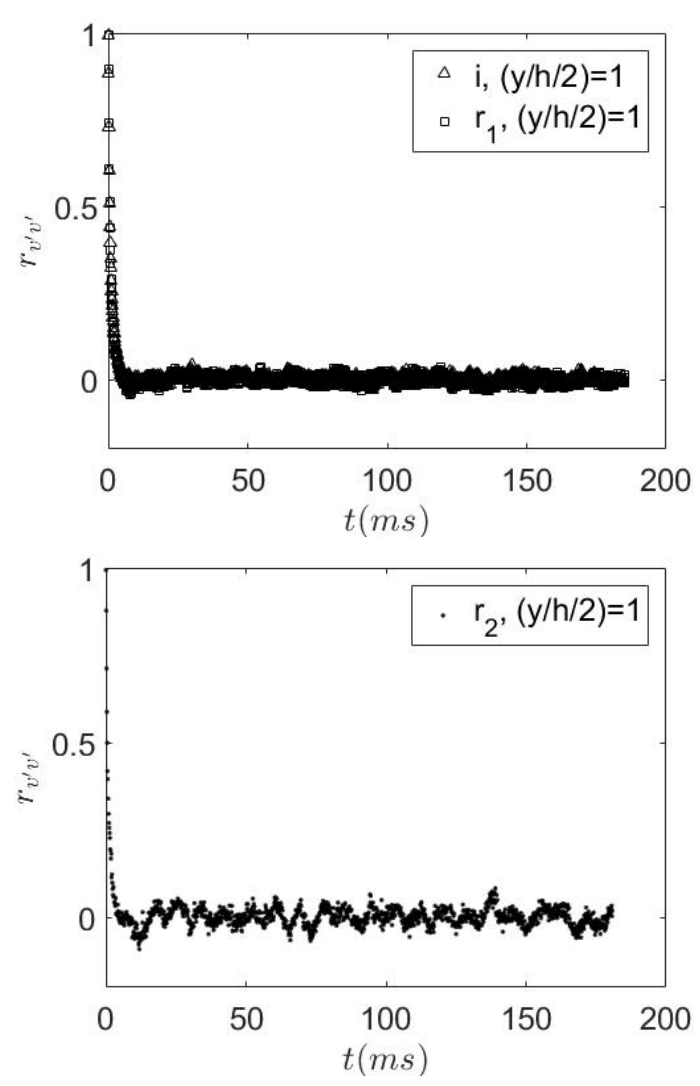

Figure 11. Auto-correlation functions of the normal rms-velocity fluctuations.

The probability density function (PDF) are calculated at entrance region for $y= \pm 1.64 h$ and $y= \pm 0.5 h$ (Figs. 12 and 13). The definitions of the skewness $(S)$ and flatness $(F)$ factors are given by:

$$
\begin{gathered}
S=\frac{\overline{u^{\prime 3}}}{\overline{u^{2^{2}}}} \\
F=\frac{\overline{u^{\prime 4}}}{{\overline{u^{\prime 2}}}^{2}}
\end{gathered}
$$

The PDF shapes for the cases $i$ and $r_{1}$ are close to a Gaussian form. In the longitudinal velocity $u$, the differences between the cases $i, r_{1}$ and $r_{2}$ are clear. The range for the case $r_{2}$ is wider than $i$ and $r_{1}$. Unlike what is observed for cases $i$ and $r_{1}$, the PDF shapes of the case $r_{2}$ from the longitudinal velocity (Fig. 12) depart from the Gaussian form with a slight bimodal character. This can be associated with the presence of periodic coherent structures in the flow (Nguyen et al., 2009). For the normal velocity $v$ (Fig. 13), the PDF shapes presents a range with the same order of magnitude for all cases studied and the bimodal character is not observed in the case $r_{2}$. 

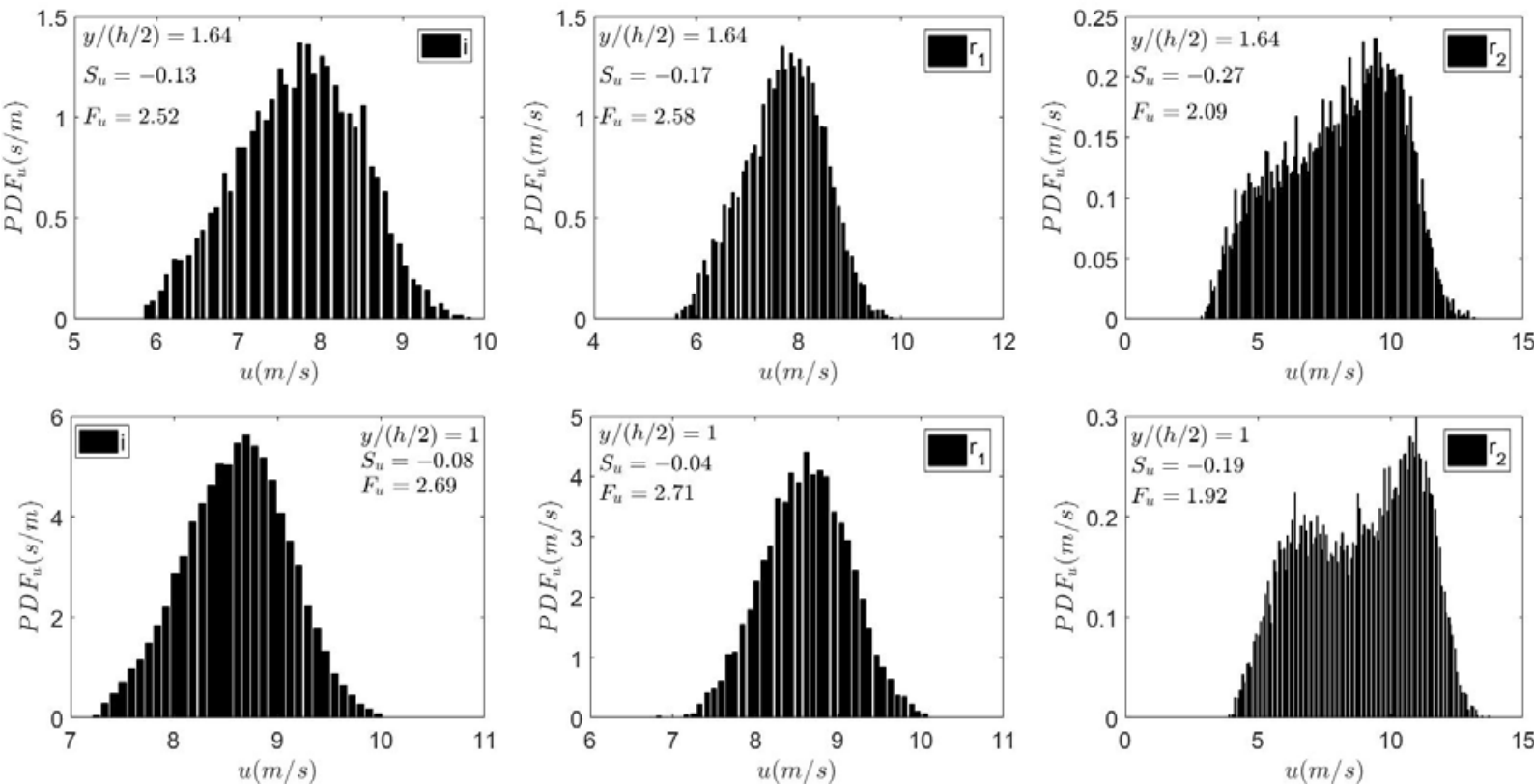

Figure 12. Probability density function (PDF) of the longitudinal velocity. (Maximum resolution $\Delta u=0.0718 \mathrm{~m} / \mathrm{s})$.
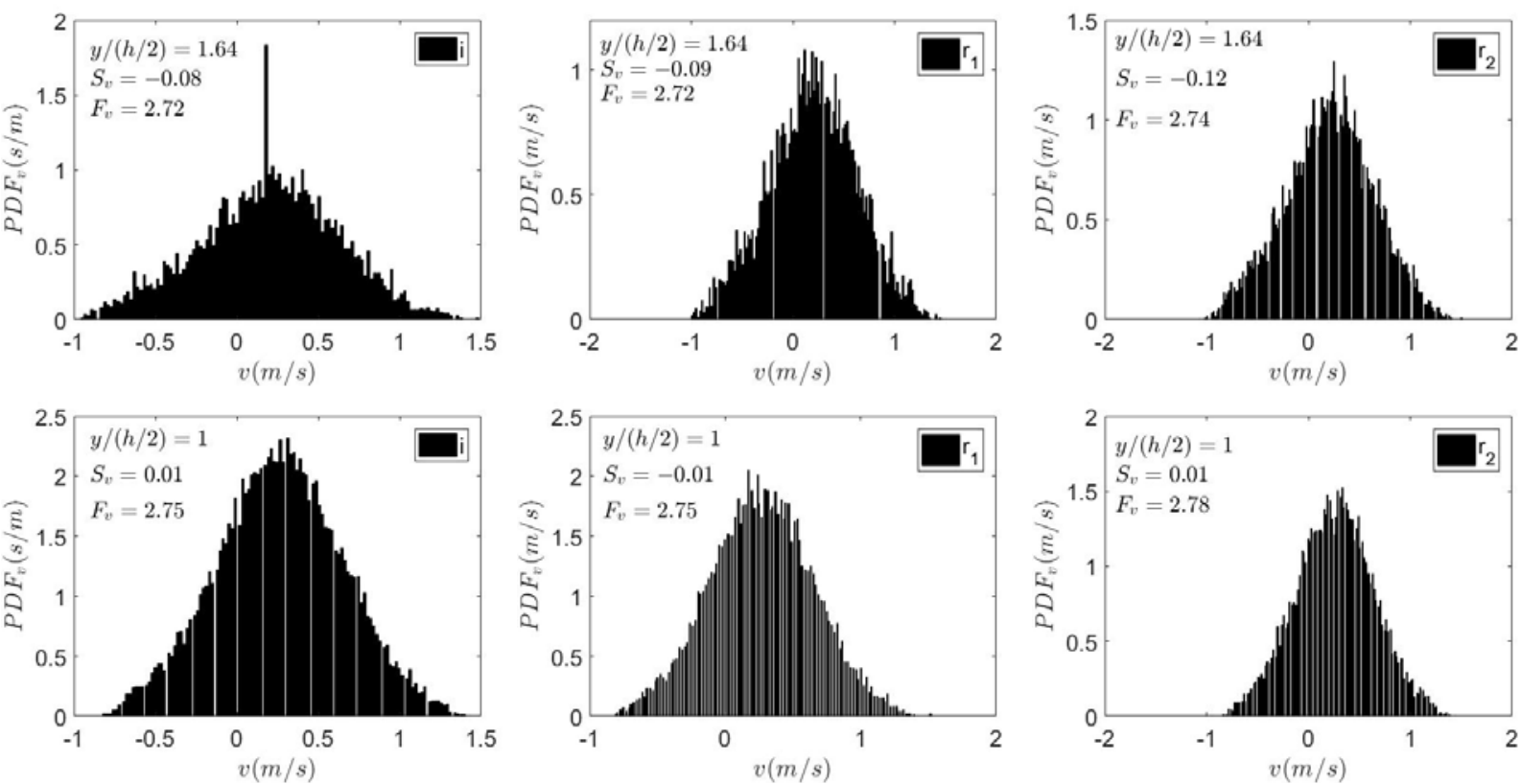

Figure 13. Probability density function (PDF) of the normal velocity (Maximum resolution $\Delta v=0.0190 \mathrm{~m} / \mathrm{s}$

Figures 14 and 15 shows the energy spectral density (ESD) of the two velocity components at the same locations as for the PDF presented in the previous paragraph. All the spectra have a form of a plateau followed by a $-5 / 3$ power law decay, behavior found in an equilibrium turbulence. For the case $r_{2}$, the spectra exhibit a peak of energy associated with a frequency of approximately $348 \mathrm{~Hz}$. This peak is not presented in the $i$ and $r_{1}$. For the longitudinal velocity a harmonic, much less energetic, is observed with a frequency of approximately $694 \mathrm{~Hz}$. The presence of this peak characterizes a coherent movement on large scales (Besson et al., 2000). This coherent movement is more energetic in the longitudinal direction than normal. Such combustion instability is typical of the bluff body and is associated with the mechanism of combustion developing in unstable shear layers at the edges of the flame holders (Schadow and Gutmark, 1992). 

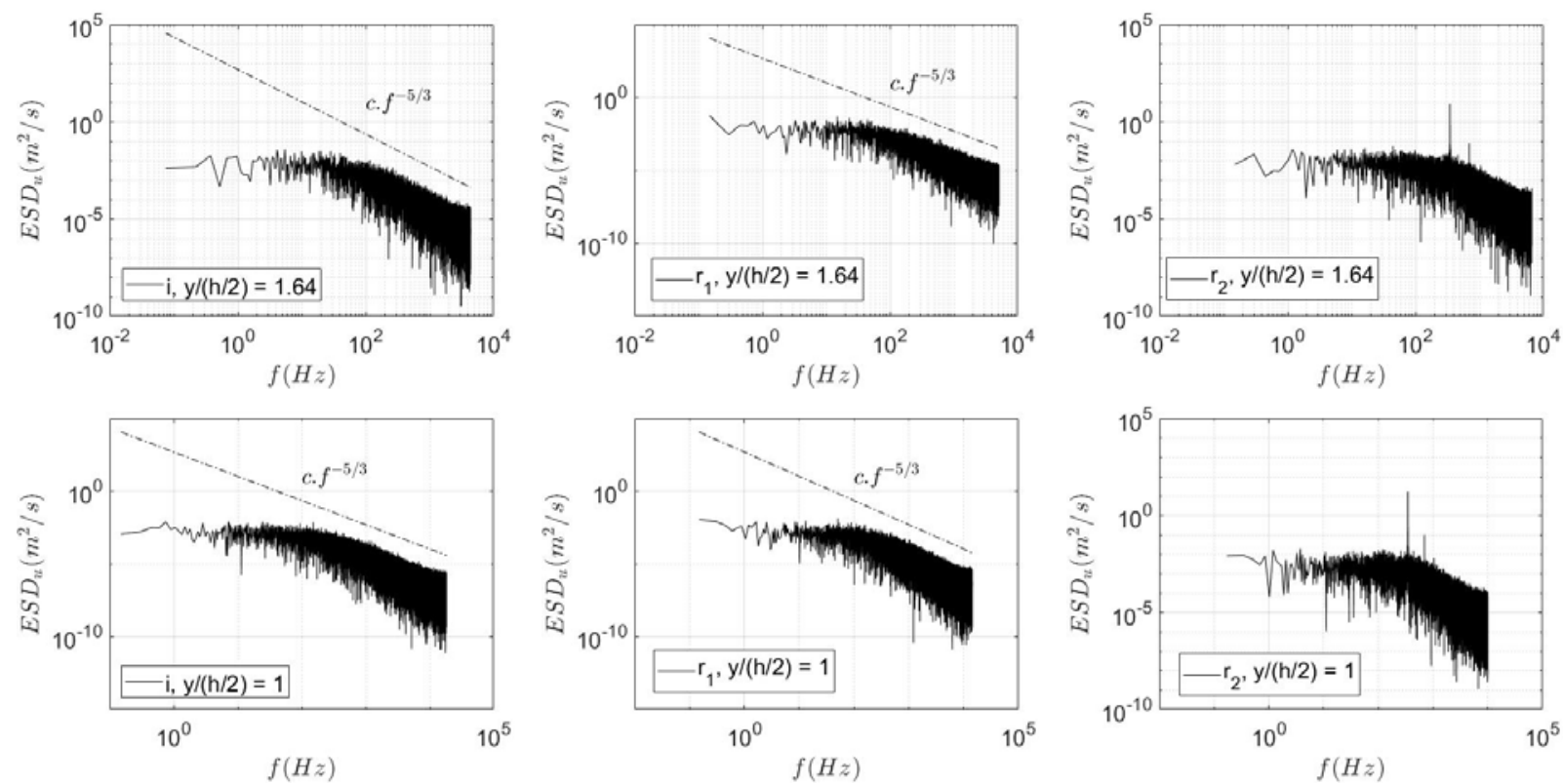

Figure 14. Energy spectral density (ESD) of the longitudinal velocity fluctuations.
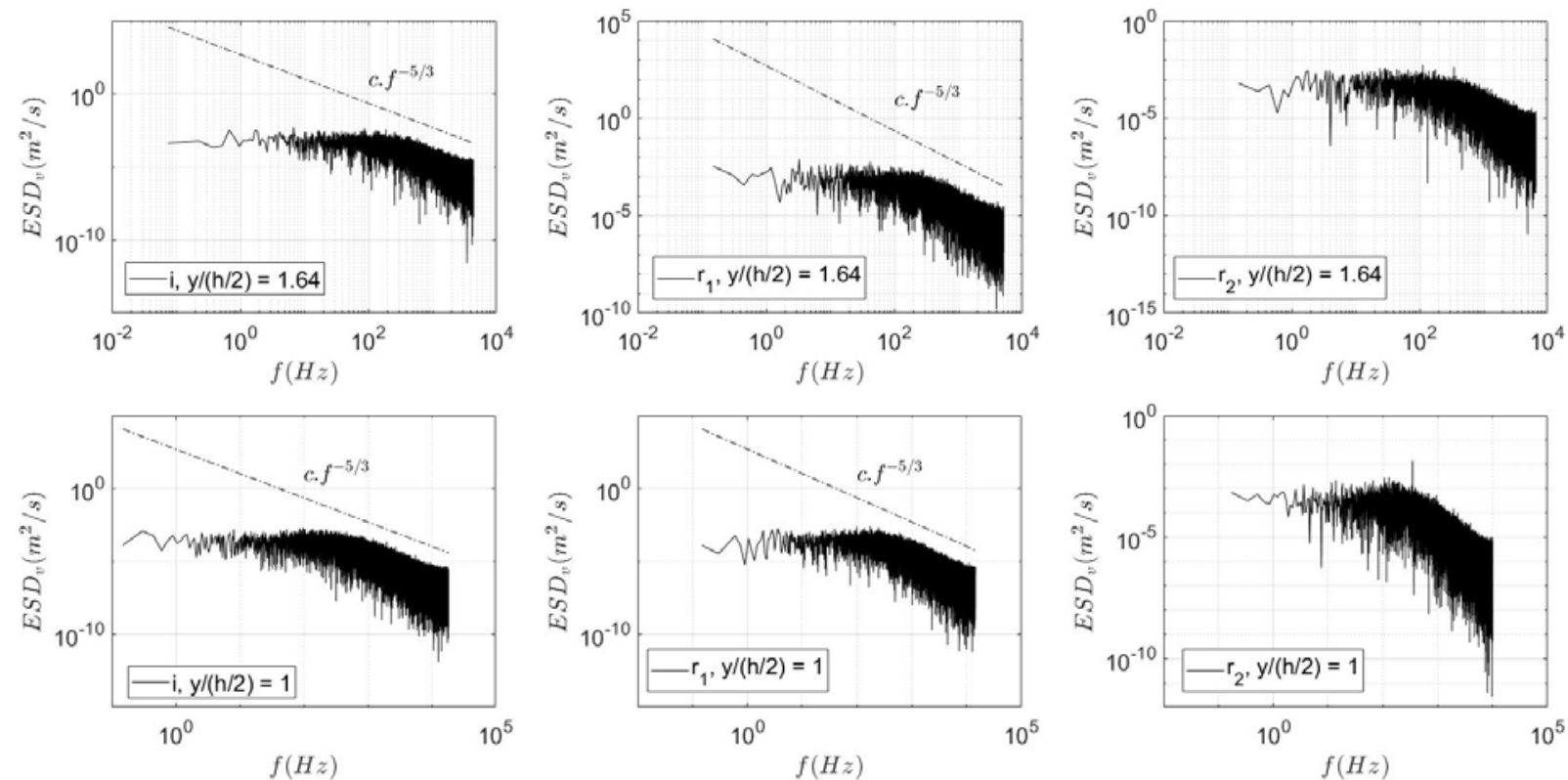

Figure 15. Energy spectral density (ESD) of the normal velocity fluctuations.

\section{CONCLUSIONS}

Experimental results were presented to evaluate the effect of combustion on the flow at the inlet of a non-premixed combustion chamber. Through velocity measurements, a comparison between inert and reacting flow was carried out.

The results showed that the incoming flows are symmetric relative to the centerline of the test bench for both inert flow and the reacting flow $r_{1}$. For those cases, the energy spectral density does not show any distinguishable peak of energy and the probability density function shapes are close to a Gaussian form. The increase of the equivalence ratio (reacting flow $r_{2}$ ) brings an asymmetry to the mean flow and an increase of the total velocity fluctuations. Such increase of the velocity fluctuations is related to the flame brush dynamics. Moreover, the presence of a peak of energy on the energy spectra and a slight bimodal character on the probability density function shows the presence of a large scales coherent movement. The incoming flow exhibit a pulsation behaviour, which is stronger in the longitudinal direction.

\section{ACKNOWLEDGEMENTS}

This research was supported by Agência 
Espacial Brasileira (AEB) and IAE through the development of the L-75 engine under the contract No. 6704. The experiments were carried out at Divisão de Propulsão Espacial, whose technical support is acknowledged. Trevisan, B.P. has been granted a $\mathrm{PhD}$ scholar ship by the Coordenação de Aperfeiçoamento de Pessoal de Nível Superior (CAPES).

\section{REFERENCES}

Albrecht, H. E., Damaschke N., Borys M., and Tropea, C., 2003, Laser Doppler and Phase Doppler Measurement Techniques, Springer.

Benedict, L. H., and Gould, R. D., 1996, Towards Better Uncertainty Estimates for Turbulence Statistics, Experiments in Fluids, Vol. 22, No. 2, pp. 129-136.

Besson, M., Bruel, P., Champion, J. L., and Deshaies, B., 2000, Experimental Analysis of Combustion Flows Developing over a PlaneSymmetric Expansion, Journal of Thermophysics and Heat Transfer, Vol. 14, No. 1, pp. 59-67.

Besson, M., 2001, Étude Expérimentaled'une Zone de Combustion en Écoulement Turbulent Stabiliséeen Aval d'um Élargissement Brusque Symétrique, Doctoral Thesis, Université de Poitiers, France. (in France)

Dourado, W. M. C., 2003, Desenvolvimento de um Método Numérico em Malhas Não-Estruturadas Híbridas para Escoamentos Turbulentos em Baixo Número de Mach: Aplicação em Chama Propagandose Livremente em Esteiras Inertes e Reativas, Doctoral Thesis, Instituto Tecnológico de Aeronáutica, Brazil. (in Portuguese)

Gianni, G., Mariotti, G., Paganini, E., and Sello, S., 2003, Characterization and Diagnostics of Combustion Thermoacoustic Instabilities Using Nonlinear Dynamics and Topological Methods, in: Proceeding of the European Combustion Meeting 2003.

Habiballah, M., Vingert, L., Duthoit, V., and Vuillermoz, P., 1998, Research as a Key in the Design Methodology of Liquid-Propellant Combustion Devices, Journal of Propulsion and Power, Vol. 14, No. 5, pp. 782.

Hassel, E. P., and Linow, S., 2000, Laser Diagnostics for Studies of Turbulent Combustion, Measurement Science and Technology, Vol. 11, pp. R37-R57.

Janus, B., Dreizler, A., and Janicka, J., 2007, Experiments on Swirl Stabilized Non-Premixed Natural Gas Flames in a Model Gas Turbine Combustor, in: Proceedings of the Combustion Institute, Vol. 33, pp. 3091-3098.

Nguyen, P. D., Bruel, P., and Reichstadt, S., 2009, An Experimental Database for Benchmarking Simulations of Turbulent Premixed Reacting Flows: lean Extinction Limits and Velocity Field Measurements in a Dump Combustor, Flow
Turbulence Combust., Vol. 82, pp. 155-183.

Sanquer, S., Bruel, P., and Deshaies, D., 1998, Some Specific Characteristics of Turbulence in the Reactive Wakes of Bluff Bodies, AIAA Journal, Vol. 36, No. 6, pp. 994-1001.

Schadow, K. C., and Gutmark, E., 1992, Combustion Instability Related to Vortex Shedding in Dump Combustors and Their Passive Control, Progress in Energy and Combustion Science, Vol. 18, pp. 117-132.

Souza, G. H. S., 2015, Estudo de Chama PréMisturada Estratificada Usando Modelo de Enrugamento de Superfície de Chama com Limite de Extinção, Doctoral Thesis, Instituto Nacional de Pesquisas Espaciais, Brazil. (in Portuguese)

Steinberg, A. M., Boxx, I., Stöhr, M., Carter, C., and Meier, W., 2010, Flow-Flame Interactions Causing Acoustically Coupled Heat Release Fluctuations in a Thermo-Acoustically Unstable Gas Turbine Model Combustor, Combustion and Flame, Vol. 157, pp. 2250-2266.

Trevisan, B. P., 2018, Um Estudo Experimental da Interação Turbulência, Combustão e Acústica, Doctoral Thesis, Instituto Nacional de Pesquisas Espaciais, Brazil. (in Portuguese)

Van Maanen, H., and Tummers, M., 1996, Estimation of the Auto Correlation Function of Turbulent Velocity Fluctuations Using the Slotting Technique with Local Normalization, in: 8th Int. Symp. on Appl. of Laser Techn. to Fluid Mechanics. 